\title{
Risk factors in patient safety: minimally invasive surgery versus conventional surgery
}

\author{
Sharon P. Rodrigues • Aurystella M. Wever • \\ Jenny Dankelman · Frank W. Jansen
}

Received: 11 January 2011/ Accepted: 29 July 2011/Published online: 5 September 2011

(c) The Author(s) 2011. This article is published with open access at Springerlink.com

\begin{abstract}
Background This study aimed to identify the frequency of events in the different patient safety risk domains during minimally invasive surgery (MIS) and conventional surgery (CS).

Methods A convenience sample of gynecologic MIS and CS was observed. Events were observed and categorized into one of the predefined patient safety risk domains.

Results A total of 53 procedures were observed: $26 \mathrm{CS}$ and 27 MIS procedures. The general characteristics were comparable between the two groups. A large number of environmental events were observed, averaging one every $2.5 \mathrm{~min}$. Technical events and events of an organizational nature occurred more often in MIS $(P<0.01)$ than in CS $(P<0.01)$. The relative risk for the occurrence of one or more technical events in MIS compared with CS was 1.7, and the risk for two or more technical events was 4.1. A time out according to protocol showed no relationship to the occurrence of the different types of patient safetyrelated events.

Conclusion The technological complexity inherent in MIS makes this type of surgery more prone to technologyrelated problems than CS, even in a specially designed minimally invasive surgical suite. A regular time-out procedure developed for CS lacks the attention necessary for the complex technology used in MIS and therefore is insufficient for MIS procedures briefing. Incorporating a
\end{abstract}

S. P. Rodrigues $(\varangle)$ · A. M. Wever · F. W. Jansen Department of Gynecology, Leiden University Medical Center, P.O. Box 9600, 2300, RC, Leiden, The Netherlands e-mail: S.P.Rodrigues@lumc.nl

J. Dankelman · F. W. Jansen

Department of BioMechanical Engineering,

Delft University of Technology, Delft, The Netherlands specially designed technology checklist in a regular briefing protocol could be a solution to decrease the number of events in MIS.

Keywords Minimally invasive surgery - Patient safety . Risk factor $\cdot$ Safety $\cdot$ Surgery $\cdot$ Systems approach

Ever since the Harvard medical practice study and the report by the Institute of Medicine (IOM), To Err Is Human: Building a Safer Health System, that followed it, patient safety has become a major focus of improvement in health care. As is widely known, an estimate stated by the IOM alleged that 44,000-98,000 patients die every year in the United States due to medical errors [1].

In the Netherlands, the results of a national study assessing the number of hospital adverse events were presented in 2007. This study showed that $5.7 \%$ of 1.3 million patients admitted in 2004 encountered an adverse event. For $40 \%$ of these patients, the adverse event probably could have been prevented [2]. This high percentage of preventability is confirmed in a systematic review [3] including eight studies with a total of 74,485 patients. The median incidence of hospital adverse events reported in this study was $9.2 \%$, and the median percentage of preventability was reported to be $43.5 \%$. Of these hospital adverse events, $39.6 \%$ were operating room (OR) related.

In 2007, the report by the Dutch inspectorate of health care [4] emphasized that the complexity of minimally invasive surgery (MIS) further increases risks in patient safety. However, the mechanism whereby patient safety in MIS is more compromised than in conventional surgery (CS) remains unclear. To understand this mechanism, differences in patient safety between the two types of 
Fig. 1 Framework of risk domains explaining patient safety in surgery according to a systems approach

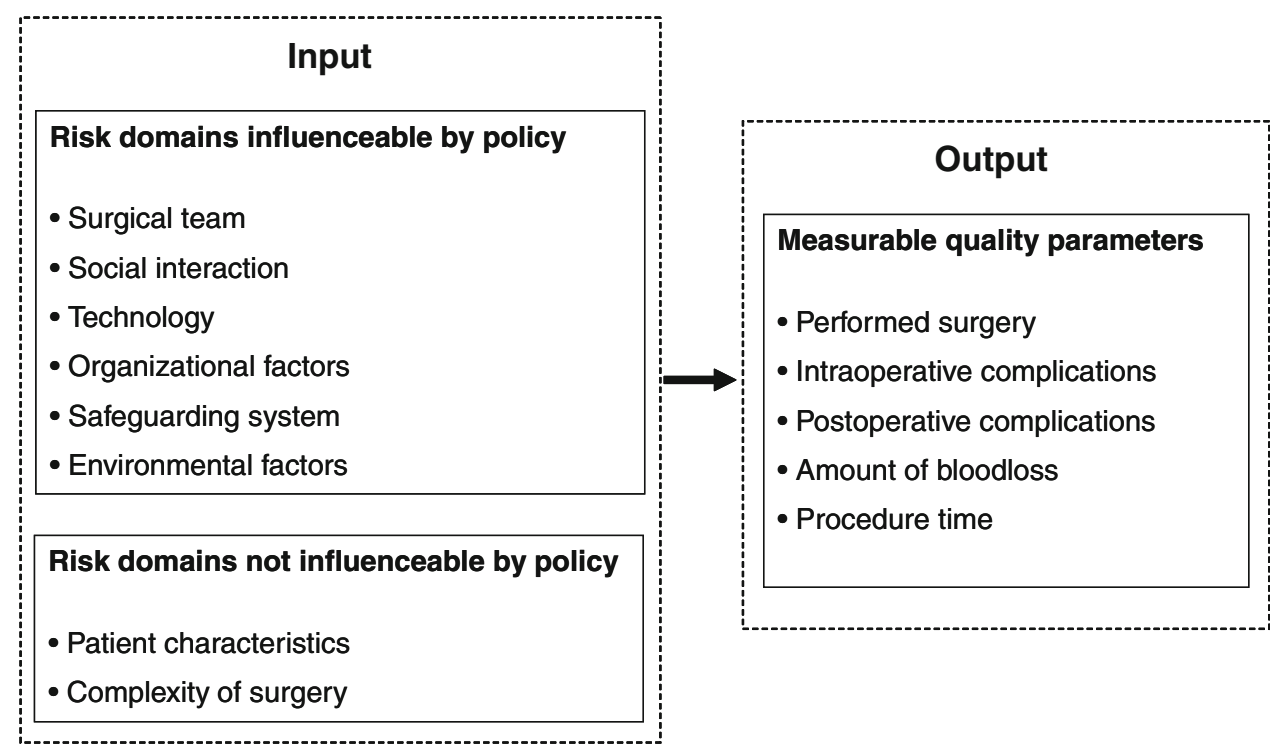

surgery should be investigated according to the systems approach. This approach to quality and safety in surgery is required to obtain insight into causes of errors and has a much larger effect on patient safety than the person approach [5].

Several important studies have suggested frameworks of factors that influence patient safety based on the systems approach [6-8]. These frameworks were adapted to explain patient safety during surgery in terms of several risk domains and measurable quality outcome parameters (Fig. 1). This observational study aimed to identify differences in patient safety risk factors between MIS and CS according to the systems approach.

\section{Material and methods}

Case selection

A convenience sample of gynecologic MIS and CS performed at the Leiden University Medical Center, the Netherlands, was observed. During the study, CS performed in an OR with regular OR settings was observed. Only MIS procedures performed in minimally invasive surgical suites especially designed for laparoscopy (in this case, OR-1, Karl Storz) were included because these suites were especially designed to facilitate MIS [9, 10].

In this study, MIS comprised only laparoscopies and was stratified based on the level of difficulty according to the guidelines of the Royal College of Obstetricians and Gynecologists (RCOG) [11]. The RCOG levels range from level 1 procedures, which are basic laparoscopic procedures (e.g., diagnostic laparoscopy and sterilization), to level 3 procedures, which are advanced laparoscopic procedures (e.g., total laparoscopic hysterectomy). The procedures that could not be classified as MIS were categorized as CS.

\section{Categorization system}

The adapted framework, which explains patient safety in terms of several risk domains and measurable quality outcome parameters (Fig. 1), was the basis for the observations in this study. For an objective assessment of the risk domains in the framework, every risk domain should be quantified. This quantification and further categorization of the observations is explained in Table 1.

The categorization was tested in a pilot study during a period of 3 weeks. During this pilot study, random gynecologic surgical procedures were observed according to the categorization. After every procedure, individual surgical team members evaluated the procedure with the researcher to determine the feasibility of the categorization.

Next, the categorization was critically reviewed for clinical relevance and completeness by a board of three independent experts (all authorities in the field of patient safety and MIS representing the department of surgery, gynecology, and patient safety in general). The final categorization system, shown in Table 1 , comprised a number of risk domains that had to be quantified during the observations (e.g., social interaction, technology, safeguarding system, organization, and environment). This was achieved by observing the number of events that could be categorized in these risk domains. 
Table 1 Framework to which observations are categorized

\begin{tabular}{|c|c|c|}
\hline Risk domain & Influencing factor & Observation (quantity) \\
\hline \multicolumn{3}{|l|}{ Input } \\
\hline Surgical team & $\begin{array}{l}\text { Knowledge and } \\
\text { experience of } \\
\text { individual team } \\
\text { member }\end{array}$ & $\begin{array}{l}\text { Experience of every } \\
\text { individual team member } \\
\text { defined as the estimated } \\
\text { number of similar } \\
\text { procedures previously } \\
\text { performed }\end{array}$ \\
\hline \multirow[t]{2}{*}{$\begin{array}{l}\text { Social } \\
\text { interaction }\end{array}$} & $\begin{array}{l}\text { Verbal and nonverbal } \\
\text { communication }\end{array}$ & $\begin{array}{l}\text { Events concerning verbal } \\
\text { miscommunication }\end{array}$ \\
\hline & Teamwork & $\begin{array}{l}\text { Events concerning } \\
\text { teamwork }\end{array}$ \\
\hline \multirow[t]{2}{*}{ Technology } & $\begin{array}{l}\text { Availability and } \\
\text { functioning of } \\
\text { equipment and } \\
\text { instruments }\end{array}$ & $\begin{array}{l}\text { Events concerning the } \\
\text { presence or correct } \\
\text { positioning of } \\
\text { instruments or } \\
\text { equipment }\end{array}$ \\
\hline & & $\begin{array}{l}\text { Events concerning the } \\
\text { functioning of } \\
\text { instruments or } \\
\text { equipment }\end{array}$ \\
\hline \multirow[t]{4}{*}{ Organization } & Staffing and planning & Adequate scheduling \\
\hline & & Adequate staffing \\
\hline & Availability of & Availability of supplies \\
\hline & recourses & $\begin{array}{l}\text { Availability of } \\
\text { technological items }\end{array}$ \\
\hline $\begin{array}{l}\text { Safeguarding } \\
\text { system }\end{array}$ & $\begin{array}{l}\text { Compliance of } \\
\text { policies adapted for } \\
\text { patient safety }\end{array}$ & $\begin{array}{l}\text { Correct execution of the } \\
\text { time-out procedure }\end{array}$ \\
\hline \multirow[t]{5}{*}{ Environment } & \multirow{5}{*}{$\begin{array}{l}\text { Case-irrelevant } \\
\text { disturbing factors }\end{array}$} & Door movements \\
\hline & & Telephone calls \\
\hline & & Pager calls \\
\hline & & Radio use \\
\hline & & $\begin{array}{l}\text { Case-irrelevant } \\
\text { conversation }\end{array}$ \\
\hline \multirow{2}{*}{$\begin{array}{l}\text { Patient } \\
\text { characteristics }\end{array}$} & \multirow{2}{*}{$\begin{array}{l}\text { Condition of the } \\
\text { patient }\end{array}$} & ASA score \\
\hline & & BMI \\
\hline \multirow[t]{2}{*}{$\begin{array}{l}\text { Complexity of } \\
\text { surgery }\end{array}$} & \multirow[t]{2}{*}{$\begin{array}{l}\text { Difficulty level of the } \\
\text { surgery }\end{array}$} & $\begin{array}{l}\text { MIS: type of procedure } \\
\text { that can be categorized } \\
\text { in RCOG levels }\end{array}$ \\
\hline & & CS: type of procedure \\
\hline
\end{tabular}

Output

Performed

procedure

Intraoperative

complication

Postoperative

complication

Blood loss

Procedure time

\section{Events}

Events were defined as occurrences that potentially increase risks and thus compromise patient safety, either directly or indirectly.

\section{Observations}

Observation of events during a surgical procedure started with the time out and ended when the last suture was placed. The total observational time (from time out until the last suture) and the total procedure time (from first incisions until last suture) were recorded. Furthermore, the risk domains not quantified by events and the other outcome parameters of the procedure were recorded as defined in Table 1.

Data collection

Data collection was performed by an independent observer who had not been involved in the development of the categorization to ensure objective assessment of the risk domains. This observer was required to have ample knowledge of medical processes but no knowledge of the specific procedures that had to be observed. Therefore, a medical student with 4 years of medical training was selected to be the observer.

The observer attended gynecologic surgical procedures during a training period of 3 weeks before the study to obtain familiarity with these procedures. During this period, the observer learned to recognize deviations from standard procedure as events and to code events according to the categorization.

\section{Data analysis}

All data were analyzed with the SPSS 16.0 software package (SPSS, Chicago, IL, USA). Differences in frequency of events, experience of surgical team members, and length of surgery between MIS and CS were assessed with the independent samples $t$-test. Differences in categorical data (e.g., patient characteristics) were assessed with the chi-square test.

\section{Results}

\section{General characteristics}

A total of 53 procedures were observed: 26 CS and 27 MIS procedures. The CS comprised 5 laparotomies for a benign 
indication, 5 laparotomies for a malignant indication, 9 vaginal hysterectomies including 4 combined with prolapse surgery, 6 vulva surgeries, and 1 cervical procedure. The MIS comprised 10 RCOG level 1 procedures, 11 level two procedures, and 6 level three procedures.

Both the mean total observational time and the mean total procedure time were comparable between MIS (1 h $29 \mathrm{~min}$ vs. $1 \mathrm{~h} 52 \mathrm{~min})$ and CS ( $1 \mathrm{~h} 19 \mathrm{~min}$ vs. $1 \mathrm{~h}$ $44 \mathrm{~min})$. The mean experience of the surgical team members did not differ between MIS and CS. The body mass indexes (BMI) and the American society of anesthesiology (ASA) scores of the patients were both comparable between MIS and CS (Table 2).

\section{Events}

The total counts of observed events are displayed in Table 2. Between 75 and $100 \%$ of the events occurred intraoperatively, as illustrated in Fig. 2. The greatest number of observed events were categorized under environment (MIS 90\% vs. CS 97\%). Of these events, door movements were observed most: MIS 81\% $(n=925)$ versus CS $80 \%(n=1,275)$. All observed events were checked for a correlation with the length of surgery, which was found for telephone calls $\left(R^{2}=0.71\right)$ and door movements $\left(R^{2}=0.74\right)$. One door movement occurred every $154 \mathrm{~s}$ in MIS compared with one every $140 \mathrm{~s}$ in CS, and one telephone call occurred every $20 \mathrm{~min}$ in both MIS and CS. All environmental events combined showed an average of one event observed every 125 s during MIS and

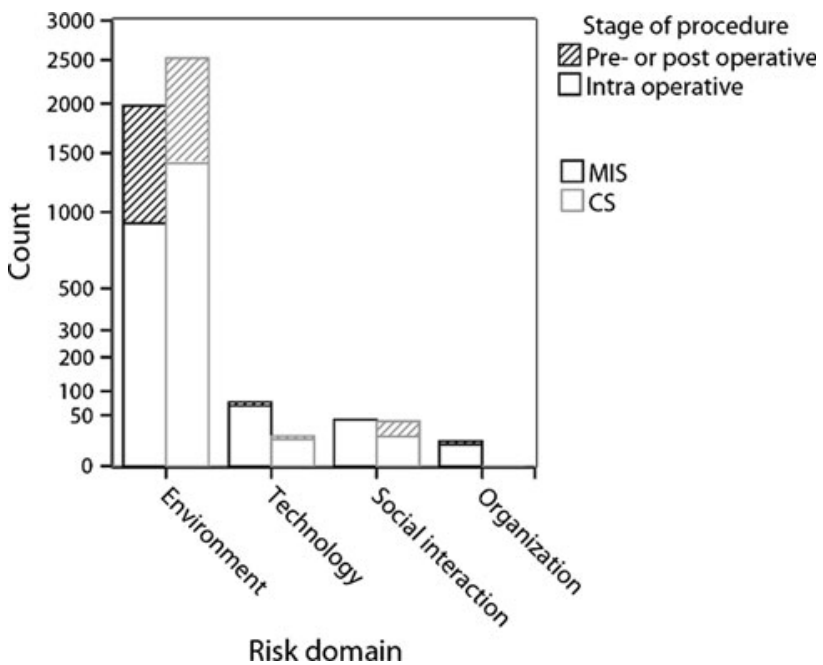

Fig. 2 Total counts of observed events in minimally invasive surgery $(M I S)$ and conventional surgery $(C S)$. The striped part represents the share of events that occurred pre- or postoperatively, and the white part represents the share of events that occurred intraoperatively

one observed every $111 \mathrm{~s}$ during CS. Of these observed environmental events, $8.8 \%$ were noted as disturbing by the surgeon in MIS compared with $17.6 \%$ in CS.

\section{MIS versus CS}

The comparative frequencies of the different types of events in MIS and CS showed no difference between environmental and social events except for disturbance of
Table 2 Count of events during the total observational time
MIS minimally invasive surgery; $C S$ conventional surgery; Count total count of all procedures; Max count highest count reached during one procedure; Mean per procedure (count divided by number of procedures) if no correlation was found between count and procedure time; $N S$ not significant

a Per minute if a correlation was found between count and procedure time (count divided by procedure time)

\begin{tabular}{|c|c|c|c|c|c|c|c|c|}
\hline & \multicolumn{3}{|c|}{$\operatorname{MIS}(n=27)$} & \multicolumn{3}{|c|}{$\mathrm{CS}(n=26)$} & \multirow[t]{2}{*}{ Total } & \multirow{2}{*}{$\begin{array}{l}\text { MIS vs CS } \\
P \text { value }\end{array}$} \\
\hline & Count & $\begin{array}{l}\text { Max } \\
\text { count }\end{array}$ & Mean & Count & $\begin{array}{l}\text { Max } \\
\text { count }\end{array}$ & Mean & & \\
\hline \multicolumn{9}{|l|}{ Environmental } \\
\hline Total & 1,145 & 114 & $0.48^{\mathrm{a}}$ & 1,594 & 208 & $0.54^{\mathrm{a}}$ & 2739 & NS \\
\hline Door movements & 925 & 90 & $0.39^{\mathrm{a}}$ & 1,275 & 174 & $0.43^{\mathrm{a}}$ & 1812 & NS \\
\hline Telephone & 112 & 11 & $0.05^{\mathrm{a}}$ & 165 & 28 & $0.05^{\mathrm{a}}$ & 268 & NS \\
\hline Beeper & 41 & 8 & 1.52 & 77 & 13 & 2.96 & 118 & NS \\
\hline Radio & 9 & 2 & 0.33 & 20 & 2 & 0.77 & 29 & $<0.01$ \\
\hline Case-irrelevant conversation & 58 & 11 & 2.15 & 57 & 9 & 2.19 & 115 & NS \\
\hline \multicolumn{9}{|l|}{ Technical } \\
\hline Total & 69 & 8 & 2.56 & 18 & 3 & 0.69 & 87 & $<0.01$ \\
\hline Equipment & 45 & 6 & 1.67 & 11 & 2 & 0.42 & 56 & $<0.01$ \\
\hline Instruments & 24 & 2 & 0.89 & 7 & 3 & 0.12 & 31 & $<0.01$ \\
\hline \multicolumn{9}{|l|}{ Social } \\
\hline Total & 43 & 9 & 1.59 & 27 & 8 & 1.04 & 70 & NS \\
\hline Communication & 34 & 7 & 1.26 & 22 & 7 & 0.85 & 56 & NS \\
\hline Teamwork & 9 & 2 & 0.33 & 5 & 1 & 0.19 & 14 & NS \\
\hline \multicolumn{9}{|l|}{ Organizational } \\
\hline Total & 13 & 3 & 0.48 & 0 & 0 & 0.00 & 13 & $<0.01$ \\
\hline
\end{tabular}


the radio, which was noted more often during CS $(P<0.01)$. Technical events and events of an organizational nature occurred more often during MIS $(P<0.01)$ than during $\operatorname{CS}(P<0.01)$ (Table 2).

Among all the events of a technical nature observed during MIS, $49 \%(n=34)$ were problems with the positioning of equipment or instruments. Problems with the functioning of equipment or instruments accounted for $28 \%$ of these events $(n=19)$.

In CS, 33\% $(n=6)$ of the observed events of a technical nature were positional and $28 \%(n=5)$ were problems with functioning. Among the 13 problems of an organizational nature observed during MIS, 8 involved the unavailability of instruments at the time of surgery. The other organizational problems were a result of inadequate staffing.

\section{Relative risk}

The relative risk calculated for the occurrence of one or more events of a technical nature in MIS compared with CS was 1.7. The relative risk of having two or more technical problems during MIS versus CS was 4.1. For organizational problems, the relative risk could not be calculated because none occurred during CS.

\section{Time out}

The time-out protocol used in the observed clinic was similar to the time-out protocol developed by the World Health Organization (WHO) [12]. In 74\% of the MIS procedures, the time out proceeded according to this protocol compared with $50 \%$ of the CS procedures. One MIS procedure and five CS procedures had no time out at all. However, no relation between a time-out procedure according to the protocol and the occurrence of different types of patient safety-related events was observed.

\section{Discussion}

Differences in patient safety-related events between CS and MIS can be explained by the use of advanced technology as an essential part of MIS. This is consistent with the statement made by the Dutch Inspectorate of health care that the (technical) complexity of MIS further increases risks in patient safety compared with CS. A previous study has already shown that a great number of technical events tend to occur during laparoscopic procedures. In fact, in $87 \%$ (26 of 30) of the observed laparoscopic procedures, one or more incidents with technical equipment $(n=46)$ or instruments $(n=9)$ occurred [13].
Surgeons may be aware of the implications of new technology for patient safety. However, to our knowledge, the consequences of technology for events that occur in the OR have never been described. Our data show that the majority of the organizational events $(62 \%)$ also were technology related. More specifically, they were related to the preparation for the technological aspect of MIS (missing instruments or equipment). Altogether, it appears to be particularly the advanced technology added to surgery that hinders patient safety in MIS compared with CS.

Although studies prove that general briefing checklists reduce morbidity and mortality in surgery $[12,14]$, the results of the current study suggest that for MIS a different approach is required. The fact that a time out according to protocol is not correlated with a lower frequency of events leads us to speculate that a general briefing procedure such as the WHO checklist is insufficient for the preparation for MIS.

Because the most important difference in events between MIS and CS is in the frequency of technologyrelated events, more attention is needed for technology during the briefing. An adequate solution already shown to reduce the number of technical events in MIS is the use of a standardized checklist especially designed for MIS [15]. Such a checklist could be incorporated into the general WHO briefing for MIS cases.

In the current study, an astonishing number of environmental events occurred about every $2 \mathrm{~min}$ in both MIS and CS. These events consisted primarily of door movements (one very $2.5 \mathrm{~min}$ ) with the potential risk of surgical-site infections.

High frequencies of door movements have been reported previously, namely, 13-316 times per surgery (5-87 per recorded hour) [16]. Similar to the findings of the current study, the observed door movements increased in direct proportion to the length of surgery and also were related to the number of persons in the OR. It is remarkable that the bulk of environmental events were not observed to be disturbing or distracting to the senior surgeon because $8.8 \%$ of all the observed environmental events combined were disturbing in MIS compared with $17.6 \%$ in CS. The reason for this could be that experienced surgeons have learned to block distracting events and remain concentrated [17] and that most environmental events do not occur during critical moments.

However, the effect of environmental events should not be underestimated. Especially the performance of inexperienced surgeons or residents could be influenced by distraction, as shown in a previous study [18].

Findings have shown that social factors such as communication and teamwork are important risk factors in patient safety. In fact, optimizing teamwork to reduce error 
stands as the basis of a whole new era of research: crew resource management.

Communication difficulties previously have been reported to occur in approximately $30 \%$ of team exchanges [19]. About one third of the communication failures resulted in visible effects that could influence patient safety [20]. In the current study, however, the frequency of the observed social events was very low compared with that described in previous reports. The most obvious reason could be an underestimation of the true quantity of these events. The previously published studies focused only on communication (or teamwork) events, also reporting small social mishaps, whereas the current study focused also on technical, organizational, and environmental events. The social events reported in this study needed to be prominently present and therefore more prone to influence safety than small social mishaps, which might not have had any influence at all. Furthermore, because observations of both MIS and CS were done by the same observer, a comparable (under)estimation is to be expected for both types of surgery, and a relative comparison remains possible. Hence, it can be stated that is no difference exists in the number of observed events of a social nature between MIS and CS.

Another observational study investigated different types of surgical flow disruptions during cardiac surgery, showing that the greatest number of observed surgical flow disruptions were of a social nature (52\%) [21]. This is in contrast to our observations in MIS, indicating that the highest percentage of events are disturbing environmental events $(44.7 \%)$, followed by events of a technical nature $(30.5 \%)$. Events of a social nature accounted for only $19 \%$ of the observed events. In CS, the highest percentage of observed events were disturbing environmental events $(86.2 \%)$ followed by events of a social nature $(8.3 \%)$. Technical events during cardiac surgery accounted for $5.5 \%$ of the events. Hence, the outcome is highly procedure dependent.

A pitfall of all observational studies is observational bias. We attempted to reduce observational bias by selecting an independent researcher to perform the observations. Ideally, more than one observer should have observed all procedures to test for interrater agreement. However, this would have crowded the OR because the observations were done in an academic hospital where professionals in training (students, nurses, interns, and residents) also attend surgical procedures, and more observers would not have been in the interest of patient safety. Furthermore, it is well recognized that the Hawthorne effect (awareness of being observed alters the way a person behaves) [22] takes place. Taking this into consideration, the most accurate method for performing observations of surgical procedures probably is with some sort of black box in which video and audio recordings are made. With this approach, less influence of the Hawthorne effect and multiple independent observations would be possible.

\section{Conclusion}

A large number of events have been observed during both MIS and CS. The technological complexity inherent in MIS makes this type of surgery more prone to technologyrelated events than $\mathrm{CS}$, even in a specially designed minimally invasive surgical suite. A regular time-out procedure as used for CS lacks the necessary attention for the complex technology used in MIS and is therefore insufficient for MIS procedures briefing. Incorporating a specially designed technology checklist into a regular briefing protocol could be a solution to decrease the number of events in MIS.

Acknowledgments The authors thank D. D. Rodrigues for the technical support. They thank all the gynecologists, anesthesia personnel, and OR nurses who assisted during the observed procedures at the Leiden University Medical Center for their input, cooperation, and support during the observation period.

Disclosures Sharon P. Rodrigues, Aurystella M. Wever, Jenny Dankelman, and Frank-Willem Jansen have no conflicts of interest or financial ties to disclose.

Open Access This article is distributed under the terms of the Creative Commons Attribution Noncommercial License which permits any noncommercial use, distribution, and reproduction in any medium, provided the original author(s) and source are credited.

\section{References}

1. Kohn LT, Corrigan JM, Donaldsen MS (1999) To err is human: building a safer health system. National Academy Press, Washington

2. De Bruijne MC, Zegers M, Hoonhout LH, Wagner C (2007) Onbedoelde schade in Nederlandse ziekenhuizen. Dossieronderzoek van ziekenhuisopnames in 2004. EMGO Instituut/VUmc en NIVEL, Amsterdam/Utrecht

3. de Vries EN, Ramrattan MA, Smorenburg SM, Gouma DJ, Boermeester MA (2008) The incidence and nature of in-hospital adverse events: a systematic review. Qual Saf Health Care 3:216-223

4. Inspectie voor de gezondheidszorg (2007) Risico's minimaal invasieve chirurgie onderschat, kwaliteitssysteem voor laparoscopische operaties ontbreekt. IGZ, Den Haag

5. Dankelman J, Grimbergen CA (2005) Systems approach to reduce errors in surgery. Surg Endosc 8:1017-1021

6. Calland JF, Guerlain S, Adams RB, Tribble CG, Foley E, Chekan EG (2002) A systems approach to surgical safety. Surg Endosc 6:1005-1014

7. Vincent C, Moorthy K, Sarker SK, Chang A, Darzi AW (2004) Systems approaches to surgical quality and safety: from concept to measurement. Ann Surg 4:475-482

8. Leake PA, Urbach DR (2010) Measuring processes of care in general surgery: assessment of technical and nontechnical skills. Surg Innov 17(4):332-339 
9. Herron DM, Gagner M, Kenyon TL, Swanstrom LL (2001) The minimally invasive surgical suite enters the 21 st century: a discussion of critical design elements. Surg Endosc 4:415-422

10. Kenyon TA, Urbach DR, Speer JB, Waterman-Hukari B, Foraker GF, Hansen PD, Swanstrom LL (2001) Dedicated minimally invasive surgery suites increase operating room efficiency. Surg Endosc 10:1140-1143

11. Royal College of Obstetricians and Gynecologists (1994) Report of the RCOG working party on training in gynaecological endoscopic surgery. RCOG, London

12. Haynes AB, Weiser TG, Berry WR, Lipsitz SR, Breizat AH, Dellinger EP, Herbosa T, Joseph S, Kibatala PL, Lapitan MC, Merry AF, Moorthy K, Reznick RK, Taylor B, Gawande AA (2009) A surgical safety checklist to reduce morbidity and mortality in a global population. N Engl J Med 360(5):491-499

13. Verdaasdonk EG, Stassen LP, van der Elst M, Karsten TM, Dankelman J (2007) Problems with technical equipment during laparoscopic surgery: an observational study. Surg Endosc 2: 275-279

14. de Vries EN, Prins HA, Crolla RM, den Outer AJ, van Andel G, van Helden SH, Schlack WS, van Putten MA, Gouma DJ, Dijkgraaf MG, Smorenburg SM, Boermeester MA (2010) Effect of a comprehensive surgical safety system on patient outcomes. N Engl J Med 20:1928-1937

15. Verdaasdonk EG, Stassen LP, Hoffmann WF, van der Elst M, Dankelman J (2008) Can a structured checklist prevent problems with laparoscopic equipment? Surg Endosc 10:2238-2243
16. Lynch RJ, Englesbe MJ, Sturm L, Bitar A, Budhiraj K, Kolla S, Polyachenko Y, Duck MG, Campbell DA Jr (2009) Measurement of foot traffic in the operating room: implications for infection control. Am J Med Qual 1:45-52

17. Moorthy K, Munz Y, Undre S, Darzi A (2004) Objective evaluation of the effect of noise on the performance of a complex laparoscopic task. Surgery 1:25-30

18. Pluyter JR, Buzink SN, Rutkowski AF, Jakimowicz JJ (2010) Do absorption and realistic distraction influence performance of component task surgical procedure? Surg Endosc 4:902-907

19. Lingard L, Regehr G, Espin S, Whyte S (2006) A theory-based instrument to evaluate team communication in the operating room: balancing measurement authenticity and reliability. Qual Saf Health Care 6:422-426

20. Lingard L, Espin S, Whyte S, Regehr G, Baker GR, Reznick R, Bohnen J, Orser B, Doran D, Grober E (2004) Communication failures in the operating room: an observational classification of recurrent types and effects. Qual Saf Health Care 5:330-334

21. Wiegmann DA, ElBardissi AW, Dearani JA, Daly RC, Sundt TM III (2007) Disruptions in surgical flow and their relationship to surgical errors: an exploratory investigation. Surgery 5: 658-665

22. Parsons HM (1974) What happened at Hawthorne? New evidence suggests the Hawthorne effect resulted from operant reinforcement contingencies. Science 4128:922-932 